\title{
Femur boyun kırıklarında komplikasyonlar
}

\section{Complications of internally fixed femoral neck fractures}

\author{
Mehmet Arazi
}

Özel Konya Farabi Hastanesi, Ortopedi ve Travmatoloji Kliniği, Konya

\begin{abstract}
Özellikle 55-60 yaş altındaki erişkinlerde femur boyun kırıkları sıklıkla zor tedavi edilir. Gelişen tıbbi bakım tekniklerine ve implant teknolojilerindeki iyileşmiş sonuçlara rağmen, hala yüksek oranlarda istenmeyen durumlarla karşılaşımaktadır. Hastaların neredeyse \%20'sinde ikinci bir cerrahi gerekmektedir. Tedaviyi takip eden dönemde ölüm, kırık kaynamaması, enfeksiyon, implant materyallerinin erken yetmezliği, femur başının avasküler nekrozu ve femur boynunda kısalık olması sık görülen komplikasyonlardır. Gelişmiş tıbbi imkanlara rağmen, ilk yıl sonunda \%30'lara varan ölüm oranları görülmektedir. Ayrılmış kırıklarda ortaya çıkan implant yetmezliği ve kaynamama durumlarında genç hastalarda yeniden osteosentez veya proksimal femoral osteotomilerle doğal femur başı korunmaya çalışılır. Yaşlılarda ise bu durumlarda artroplasti seçkin tedavi yöntemidir. Femur başı avasküler nekrozu gelişen hastalarda çoğu kez en iyi tedavi total kalça artroplastisidir. Altmış yaş altında olmak, kadın cinsiyet ve ayrılmış kırıklar, femur başı avasküler nekrozu için risk faktörleri olarak bilinir. Komplikasyonlardan korunmak için, hastaların ilk tedavileri yapılırken teknik kurallara ve doku canlılığına azami özen gösterilmelidir.
\end{abstract}

Anahtar sözcükler: femur boyun kırıkları; osteosentez; komplikasyon; avasküler nekroz
Treatment of femur neck fractures is often challenging, especially in adults aged under 55-60 years. Despite improved medical care and modern implant technology, complication rates are still high. Nearly $20 \%$ of patients require a second surgery. Death, non-union, infection, implant failure, avascular necrosis of the femur head, and shortening of the femur neck are commonly seen complications. Despite advanced medical facilities, mortality rates of up to $30 \%$ are seen at the end of the first year of the treatment. In the cases of implant failure and non-union of the femoral neck fractures of young patients, re-osteosynthesis of the fracture or proximal femoral osteotomies are used to preserve the native femoral head. In the elderly arthroplasty is the preferred choice of treatment method. In patients who develop femoral head avascular necrosis, the best treatment is often total hip arthroplasty. Being under 60 years of age, female gender, and displaced fractures are known as risk factors for avascular necrosis of the femoral head. In order to avoid complications, optimum care should be given to technical rules and tissue viability while caring the patients.

Key words: femoral neck fractures; osteosynthesis; complication; avascular necrosis

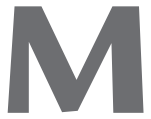

odern cerrahi tespit teknikleri ve gelişen implant teknolojisine rağmen, gençlerde femur boyun kırıklarının tedavisi hala güçlük arz etmeye devam etmektedir. Özellikle 60 yaş altındaki hastalarda görülen ayrılmış femur boyun kırıklarının tedavisi oldukça zordur. Bu nedenle de çok değişik komplikasyonlar nispeten yüksek oranlarda görülmeye devam etmektedir. Yakınlarda yayımlanan bir meta-analiz çalışmasında, femur boyun kırıklı hastaların neredeyse \%20'sinde ikinci bir cerrahinin gerekli olduğu görülmüş̧tür. ${ }^{[1]}$ Yaşlı popülasyonda erken dönemde ölüm, derin ven trombozu, enfeksiyon; genç popülasyonda ise tespit yetersizliği, avasküler nekroz (AVN), kaynama yokluğu, gibi komplikasyonlar öne çıkmaktadır. ${ }^{[2-4]}$

\section{MORTALITE}

Özellikle yaşlı popülasyonda; femur boyun kırıklarından sonra ölüm önemli bir komplikasyondur. Ölüm oranı; hastanede $\% 15$, bir yıl sonunda ise \%30'lara kadar varan oranlarda bildirilmiştir. ${ }^{[2]}$ Ölüm oranları intertrokanterik kırıklardaki oranlara benzerdir. Bu mortalite oranları, aynı yaştaki kırık olmayan insanlardan

- Illetişim adresi: Dr. Mehmet Arazi, Ferhuniye Mah. Kocatepe sok No 11. Konya

Tel: 0332 - 3518686 e-posta: mehmet.arazi@gmail.com

- Geliș tarihi: 1 Kasım $2017 \quad$ Kabul tarihi: 1 Kasım 2017 
4-5 kat daha yüksektir. Mundi ve ark. ${ }^{[5]}$ yaptıkları bir meta analizde, 31 yıllık bir dönemde (1981 ile 2012 arası) 70 klinik çalışmayı incelemişler ve femur boyun kırıkları için mortalite oranlarının bu 31 yıl içinde değişmediğini, \%20’lerde kaldığını göstermişlerdir. Komorbiditesi olanlarda ölüm oranları daha yüksektir. Ameliyata alınma süresinin mortalite etkisi çok araştırılmış bir konudur. Bu konuda tam bir fikir birliği oluştuğunu söyleyemeyiz. Çok sayıda çalışmada, erken cerrahinin mortalite oranlarını ve komplikasyonları azaltmadığı gösterilmiştir. ${ }^{[6-8]}$ Yakında yayımlanan bir çalışmada ise, Lui ve ark. ${ }^{[9]} 11$ yıllık dönemde Hong Kong şehrinde tedavi gören 65 yaş üzerindeki toplam 40.830 hastayı incelemişlerdir. Yazarlar, ilk iki günde cerrahi yapılan hastalarda geç alınanlara göre daha düşük mortalite oranları bulmuşlardır. Günümüzde mümkün olduğunca erken cerrahi tedavi yapılması önerilmektedir.

\section{TESPIT YETERSizLiĞi VE KAYNAMAMA}

Genç hastalarda, femur boyun kırıklarının internal tespiti sonrası tespit yetmezliği ve nihayetinde kaynamama önemli bir komplikasyondur. Bu iki sorunun birbirinden ayrılması da güçtür ve çoğu zaman ikisi bir aradadır. Bazen de kırık kaynaması çok uzun sürebilir ve bu da tespit yetmezliği riskini arttırabilmektedir. Serilerde, ayrılmış kırıklar için kaynamama ve implant yetmezliği oranları \%30-50 gibi yüksek değerlerde bildirilmiştir. ${ }^{[2]}$ Sloobegean ve ark. ${ }^{[1]}$ ise, yaptıkları meta-analiz çalışmasında 60 yaşın altındaki hastalarda ayrılmış kırıklarda kaynamama oranını \%9,3, tespit yetersizliğini ise $\% 9,7$ olarak vermişlerdir.

Femur boynu anatomik olarak daha sert bir kemiğe sahiptir. Ayrıca, femur boyun bölgesinde periostta kadmium tabakası yoktur. Kadmium tabakasında kırık iyileşmesini uyaran ve başlatan öncü hücreler vardır. Bu tabakanın olmaması kırık iyileşmesini olumsuz etkilemektedir. Zaten femur boynunda primer kırık iyileşmesi (kallus oluşmaksızın) görülmektedir. Bu da ancak, iyi bir kırık yüzey teması ve kompresyon ile mümkündür. Bu nedenle, tespitin başarısı komplikasyon riskini azaltmaktadır.

Genelde hastalarda kasık ağrısı, kalça hareketlerinde kısıtlılık ve yürüme güçlüğü yakınmaları gözlenir. Hastaların hemen hepsi kırık bacakları üzerine yük vermekte zorlanırlar.

Gençlerde kaynama yokluğunun nedenleri; vasküler yetmezlik, kötü ya da yetersiz kırık redüksiyonu ve tespit yetersizliği olarak sayılabilir. Tanı altı ay içinde şüpheli olmakla birlikte, genellikle ilk yıl içinde kesin olarak konur. Başın canlılığını ve kırık redüksiyonunu anlamak için manyetik rezonans (MR) görüntüleme ve bilgisayarlı tomografi (BT) kullanılır. ${ }^{2]}$
Femur boyun kırıklarının kaynama yokluğunun tedavisi değişik faktörlere bağlıdır. illk olarak yaş öne çıkar. Yaşlı hastalarda tedavi genelde artroplasti ile yapılır. Aktif yaşlılarda total kalça artroplastisi yapılırken daha ileri yaşlarda hemiartroplasti yapılır.

Genç hastalarda, eğer baş canlılığı varsa, yeniden osteosentez veya osteotomi ve tespit önerilen tedavi yaklaşımlarıdır. Baş canlılığı iyi değilse bu yaş grubunda da artroplasti yapılır.

\section{Yeniden Osteosentez}

Bu konuda bir fikir birliği olmazsa da, genellikle ilk üç hafta içince oluşan yetersiz tespitler yenilenebilir. Yeniden tespit teknik kuralları taze kırıklarda olduğu gibidir. Üç haftayı geçen durumlarda genellikle osteotomi eklenir.

\section{Proksimal Femoral Osteotomi}

Genç hastalarda, internal tespitin kaybolduğu, başın varusa gittiği, ancak baş canlılı̆ının iyi olduğu durumlarda en iyi seçenek proksimal femur valgus osteotomisidir. ${ }^{[2]}$ Valgus osteotomisi ile, vertikal olan kırık hattı biraz daha horizontal hale getirilerek, kırık uçları arasına kompresif kuwetlerin etki etmesi sağlanır. Normalde, tespit yetmezliğinde varus pozisyonu olur ve bu durumda kırık hattına makaslanma kuvvetleri etki eder. Makaslanma kuvvetleri kırık uçlarını sürekli ayırmaya çalışır, aynı zamanda implant yetmezliği riskini arttırır.

Proksimal femoral kama eksizyonu ve valgus osteotomisi, ilk kez Prof. Pauwels tarafından 1927'de tanımlanmıştır. ${ }^{[10]}$ Kendisi, çok sayıda komplike femur boyun kaynama yokluğunu kendi tanımladığı osteotomi yöntemiyle ve zamanın ilkel diyebileceğimiz tespit araçları (serklaj teli, basit çivi, gövde alçısı vb.) ile kaynatmayı ve uzun yıllar faal bir kalçanın elde edilmesini sağlamıştır. ${ }^{[10]}$ Pauwels, makaslanma kuvvetlerinin kompresif kuvvetlere çevrilmesi gerektiğini, kalça biyomekaniği ile birlikte izah etmeyi başarmıştır. Daha sonraki yıllar içerisinde, tespit için bir müddet sabit açılı kamalı plak kullanılmıştır. ${ }^{111]}$ Sabit açılı plaklar, osteotomi sonrası çok iyi bir stabilite sağlamaktadır (Şekil 1). Açılı plak tespitine ek olarak bir lag vidası, kompresyon yapmak ve ekstra rotasyonel tespit sağlamak için eklenebilir (Şekil 1 ve Şekil 2). Günümüzde ise maalesef, bu tip plaklar artık piyasada bulunmamaktadır. Üreticiler de bu tip klasik plakları artık üretmemektedir.

Diğer alternatif implantlar ise, kayıcı kalça vidası ve kilitli proksimal femur plaklarıdır. ${ }^{[12]}$ Khan ve ark., 16 femur boyun kaynama yokluğu hastasında intertrokanterik valgus ostetomisi yaptılar. Tespitte $120^{\circ}$ 'li kayıcı kalça vidası kullandılar ve takiplerde hastaların 

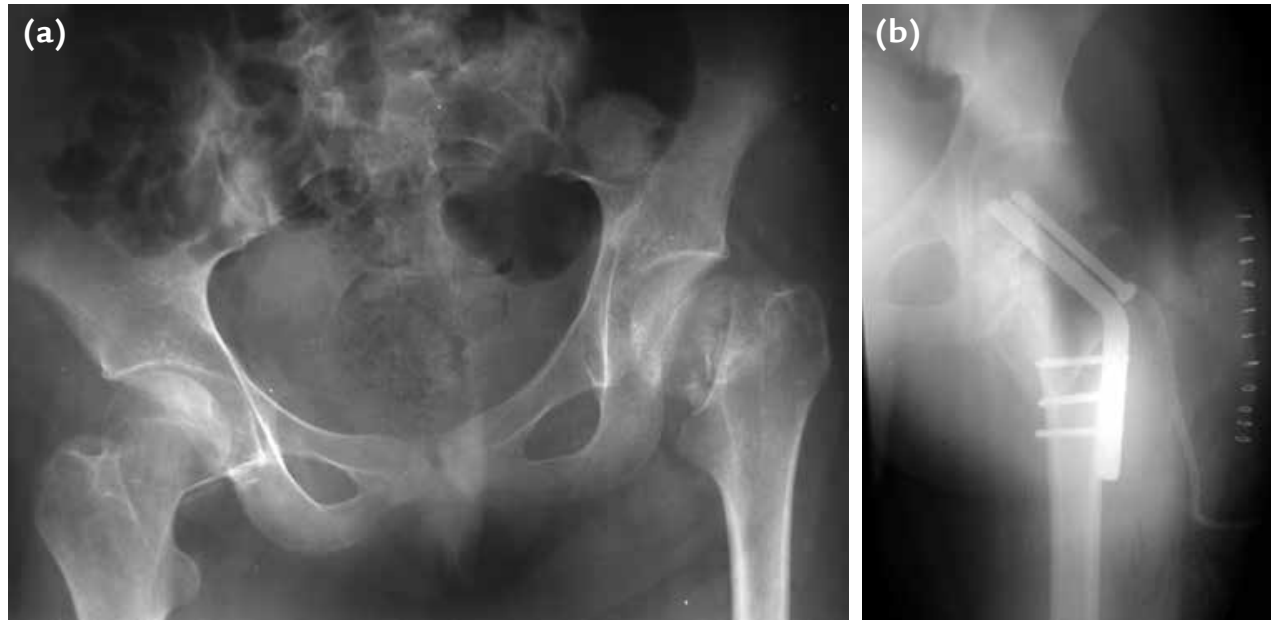

Şekil 1. a-d. Yirmi yaşındaki kadın hastada ihmal edilmiş femur boyun kırığı, üç aylık ayrılmış kırığın ön arka pelvis grafisi (a). Hastaya intertrokanterik valgus osteotomisi ve açılı plak ile internal tespit yapıldı (b, c). Hastanın tedaviden üç yıl sonraki kontrol grafisinde kırığın tamamen iyileştiği ve femur başının yuvarlaklığını koruduğu görünmektedir (d). Hasta klinik olarak da yakınmasızdı.
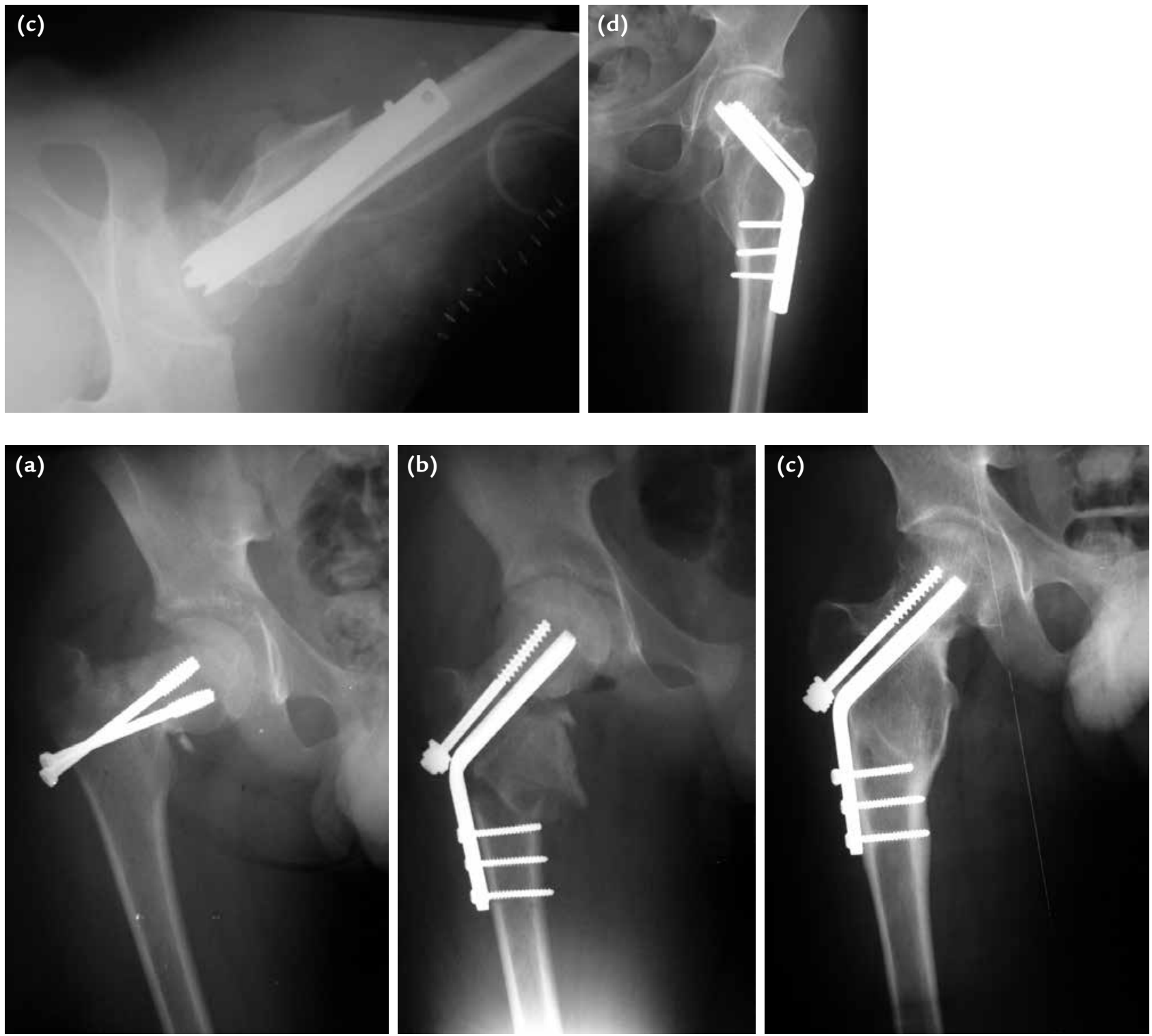

Şekil 2. a-c. On yedi yaşındaki erkek hastada iki ay önce kapalı redüksiyon ve iki adet kanüllü vida ile tespit edilen femur boyun kırığı. Kırık tespit yetersizliği görülüyor (a). Hastaya intertrokanterik valgus osteotomisi ve açılı plak ile internal tespit yapıldı (b). Hastanın tedaviden dört yıl sonraki kontrol grafisi (c). Femur boyun kırığı iyileşti ve hasta tamamen yakınmasızdı. 
14'ünde kaynama elde edildi. Yazarlar, implantın kullanımının teknik olarak kolay olduğunu ve ortopedik cerrahların tekniğe aşina olduklarını vurgulamaktadırlar. Son yıllarda, bu tip osteotomilerin tespiti için yeni jenerasyon paslanmaz çelik kilitli plaklar üretilmeye başlanmıştır. Bu tip anatomik plaklar ile, femur başına aynı anda çok sayıda kilitli (açısal stabil) vidalar konabilmektedir. Aynı zamanda kompresyona izin veren lag vidaları da sisteme eklenebilmektedir. Yine de, osteotomi ameliyatları teknik olarak zordur ve iyi bir hazırlık gerektirir. Tespit için hala ideal implantlar geliştirilememiştir.

\section{Kaynama Yokluğunda Diğer Yöntemler}

Meyers ${ }^{[13]}$, femur boynu kaynama yokluğu olgularında posterior yaklaşımla femur boynundaki kaynamama bölgesine kuadratus femoris klasının trokantere yapışma yerinden $4 \times 1,5 \mathrm{~cm}$ ebadındaki bir kemik blok ile transfer tekniğini tanımladı. Gupta ve ark. ${ }^{[14]} 32$ hastalık bir seride \%90'a varan yüksek oranda kaynama elde ettikleri bildirdiler. Baksi ve ark. ${ }^{[15]}$ yakınlarda yayımladıkları bir çalışmada, 244 hastayı Meyers tekniği ile tedavi ettiler ve olguların \%82,8'inde kaynama elde ettiklerini bildirdiler.

\section{ENFEKSIYON}

Femur boyun kırıklarının cerrahi tedavisi sonrası gelişen enfeksiyon ciddi bir komplikasyondur. Sıklıkla kalça fonksiyonlarını ciddi ölçüde bozar. Görülme oranı \%1-4 arasında bildirilmiştir. ${ }^{[16]}$ İnternal tespit yapılan femur boyun kırıklarında artroplasti yapılanlara göre enfeksiyon daha az görülmektedir. ${ }^{[17]}$ Harrison ve ark.'nın ${ }^{[18]} 3000$ olguluk bir çalışmasında, internal tespit için enfeksiyon oranı \%0,18 iken hemiartroplastiden sonra \%1,26 olarak verilmiştir. Internal tespit ile tedavi edilen hastalarda, tespit stabilitesinin sağlam olduğu ve eklem etkilenmesi olmadığı düşünülüyorsa, internal tespit materyalleri ilk etap cerrahide çıkarılmayabilir. Kırık kaynaması, iyi bir debridman ve antibiyotik baskısı ile takip edilebilir. Eğer kaynama yeterli ise internal tespit materyalleri çıkartılır. Artroplasti ile tedavi edilen hastalarda gelişen enfeksiyon durumunda ise periprostetik enfeksiyonlarda uygulanan prensipler geçerlidir.

\section{FEMUR BAŞI AVASKÜLER NEKROZU}

Femur boyun kırıklarının tedavisi sonrası AVN gelişimi, iyi bilinen ancak çok da sık görülmeyen bir komplikasyondur. Serilerde değişik görülme oranları bildirilmekle birlikte, ayrılmamış kırıklarda \%5-8, ayrılmış kırıklarda ise \%25-40'lara kadar çıkmaktadır. ${ }^{[2,4,19]}$ Yakında yapılan bir çalışmada ise Slobogean ve ark. ${ }^{[1]}$,
1552 hastalık bir meta analizde AVN oranını \%14,3 olarak vermişlerdir. Tüm serilerde, ayrılmamış kırıklarda AVN gelişme oranı düşük bildirilmiştir. AVN oluşumunda, başın ayrılma derecesi arttıkça risk artar; yine, gecikmiş redüksiyon, beraberinde kalça çıkığı olması ve yetersiz kırık redüksiyonu, diğer risk faktörleri olarak sayılabilir. ${ }^{[2]}$ Özellikle gençlerde, AVN geliştikten sonra ideal bir tedavisi yoktur; bu nedenle korunma esastır. Loizou ve Parker ${ }^{[20]} 1023$ hastalık geriye dönük bir seride, AVN oranlarını ayrılmamış kırıklar için \%4, ayrılmış kırıklar için ise \%9,5 olarak vermişlerdir. Yazarlar sonuçları değerlendirdiklerinde; 60 yaş altında olma, kadın cinsiyet ve ayrılmış kırıkları risk faktörü olarak belirtmişlerdir. Yazarlar, ameliyata kadar geçen süre ile AVN oluşumu arasında ilişki bulamamışlardır. Son yıllarda ameliyata kadar geçen sürenin AVN oluşumu riskini arttırmadığına dair hatırı sayılır sayıda çalışma yayımlanmıştır. ${ }^{[21-24]}$

AVN tanısı direkt grafi ile konulur. Ancak, çoğu olguda uzun bir sessiz dönem söz konusudur. Genellikle, AVN kırık kaynamasından sonra ortaya çıkar. MR, direkt grafiden önce AVN'yi gösterebilir. Ayrıca, sintigrafi de teşhis amaçlı kullanılabilecek bir yöntemdir. ANV gelişmiş olmasına rağmen hastalara bir cerrahi girişim yapılması şart değildir. Serilerde, önemli bir hasta grubunun asemptomatik olduğu belirtilmektedir. ${ }^{[2]}$ Semptomatik hastalarda ise uygun tedavi total kalça artroplastisidir.

\section{FEMUR BOYNUNUN KISALMASI}

Femur boyun kırıklarının tedavisi sonrası femur boynunda kısalma yaygın bir sorundur. İyileşme döneminde kanüllü vida ve DHS gibi tespit materyalleri, yapıları gereği bir miktar kompresyona izin vermektedir; bu da, kırık iyileşmesini uyarırken kırık uçlarında kısalmaya neden olmaktadır. Femur boynu kısalması ve bunun hayat kalitesine etkileri ortopedik travmada son yıllarda ilgi çeken bir alan olmuştur. Zlowodzki ve ark. ${ }^{[25]}, 5$ mm'yi geçen kısalığın hastaların hayat kalitesini olumsuz etkilediğini bildirdiler. Yaşlılarda ise kısalık oranı \%66'lara kadar varmaktadır. ${ }^{[26]}$ Daha yeni bir geriye dönük çalışmada, Stockton ve ark. ${ }^{[27]}$ yaşlı olmayan 65 hastalık seride kayıcı kalça vidası veya kanüllü vida ile tespit sonrasında 5 mm'yi geçen kısalık oranını \%54 gibi yüksek bir oranda bildirdiler. Yazarlar, hastaların \%32'sinde kısalığın $1 \mathrm{~cm}$ 'yi geçtiğini tespit ettiler. Yüksek oranda önemli derecede kısalık gözlenmesine dikkat çeken yazarlar, tedavi yöntemlerinin ve implant seçimlerinin gözden geçirilmesi gerektiğini vurgulamışlardır. Bu kısalığın yaşam kalitesine olan etkisi ise tartışma konusu olmuştur. Çok yakında yayımlanan bir çalışmada, Slobogean ve ark. ${ }^{[28]}, 1 \mathrm{~cm}$ 'yi geçen kısalığın fonksiyonel skorlara olan etkisini değerlendirdiler. Yazarlar, 55 
yaş altındaki femur boyun kırıklarının bir yıllık izlemi sonucunda, kırıkların \%13'ünde 1 cm'yi geçen kısalık tespit ettiler. Bu hastalarda Harris kalça skorları diğer hastalara göre daha düşük bulundu. Bu da, ciddi kısalığın fonksiyonel skorları olumsuz etkilediğini göstermesi açısından önemli bir bulgudur. Femur boyun kırıklarında kısalma riski bilinmeli ve hastalar bu komplikasyon konusunda da bilgilendirilmelidirler.

\section{KAYNAKLAR}

1. Slobogean GP, Sprague SA, Scott T, Bhandari $M$. Complications following young femoral neck fractures. Injury 2015;46(3):484-91. Crossref

2. Keating JF, Femoral neck fractures. In: Court-Brown CM, Heckman JD, McQuenn MM, Ricci WM, Tornetta P 3rd, editors. Rockwood and Green's Fractures in Adults, Philadelphia PA: Wolters Kluwer Health; 2015. pp.2031-75.

3. Karaeminogullari $O$, Demirors $H$, Atabek $M$, Tuncay $C$, Tandogan R, Ozalay M. Avascular necrosis and nonunion after osteosynthesis of femoral neck fractures: effect of fracture displacement and time to surgery. Adv Ther 2004;21(5):335-42.

4. Kayali C, Ağuş $H$, Arslantaş M, Turgut A. Complications of internally fixed femoral neck fractures. Ulus Travma Acil Cerrahi Derg 2008;14(3):226-30.

5. Mundi S, Pindiprolu B, Simunovic N, Bhandari M. Similar mortality rates in hip fracture patients over the past 31 years. Acta Orthop 2014;85(1):54-9. Crossref

6. Orosz GM, Magaziner J, Hannan EL, Morrison RS, Koval K, Gilbert M, McLaughlin M, Halm EA, Wang JJ, Litke A, Silberzweig SB, Siu AL. Association of timing of surgery for hip fracture and patient outcome. JAMA 2004;291(14):1738-43. Crossref

7. Sund R, Liski A. Quality effects of operative delay on mortality in hip fracture treatment. Qual Saf Health Care 2005;14(5):371-7. Crossref

8. Majumdar SR, Beaupre LA, Johnston DW, Dick DA, Cinats JG, Jiang HX. Lack of association between mortality and timing of surgical fixation in elderly patients with hip fracture: results of a retrospective population-based cohort study. Med Care 2006;44(6):552-9. Crossref

9. Liu SK, Ho AW, Wong SH, Early surgery for Hong Kong Chinese elderly patients with hip fracture reduces short-term and long-term mortality. Hong Kong Med J 2017;23(4):37480. Crossref

10. Pauwels F. Biomechanics of the Normal and Diseased Hip: Theoretical Foundation, Technique and Results of Treatment. An Atlas. Berlin: Springer Verlag; 1976. pp.1-37.

11. Marti RK, Schüller HM, Raaymakers EL. Intertrochanteric osteotomy for non-union of the femoral neck. J Bone Joint Surg Br 1989;71(5):782-7.

12. Khan AQ, Khan MS, Sherwani MK, Agarwal R. Role of valgus osteotomy and fixation with dynamic hip screw and 120 degrees double angle barrel plate in the management of neglected and ununited femoral neck fracture in young patients. J Orthop Traumatol 2009;10(2):71-8. Crossref

13. Meyers MH, Harvey JP Jr, Moore TM. Treatment of displaced subcapital and transcervical fractures of the femoral neck by muscle-pedicle-bone graft and internal fixation. A preliminary report on one hundred and fifty cases. J Bone Joint Surg Am 1973;55(2):257-74.
14. Gupta AK, Rastogi S, Nath R. Internal fixation and muscle pedicle bone grafting in femoral neck fractures. Indian J Orthop 2008;42(1):39-42. Crossref

15. Baksi DD, Pal AK, Baksi DP. Osteosynthesis of ununited femoral neck fracture by internal fixation combined with iliac crest bone chips and muscle pedicle bone grafting. Indian J Orthop 2016;50(4):366-73. Crossref

16. Bhandari M, Devereaux PJ, Swiontkowski MF, Tornetta P 3rd, Obremskey W, Koval KJ, Nork S, Sprague S, Schemitsch EH, Guyatt GH. Internal fixation compared with arthroplasty for displaced fractures of the femoral neck. A meta-analysis. J Bone Joint Surg Am 2003;85-A(9):1673-81.

17. Murphy DK, Randell T, Brennan KL, Probe RA, Brennan ML. Treatment and displacement affect the reoperation rate for femoral neck fracture. Clin Orthop Relat Res 2013;471(8):2691-702. Crossref

18. Harrison T, Robinson P, Cook A, Parker MJ. Factors affecting the incidence of deep wound infection after hip fracture surgery. J Bone Joint Surg Br 2012;94(2):237-40. Crossref

19. Damany DS, Parker MJ, Chojnowski A. Complications after intracapsular hip fractures in young adults. A meta-analysis of 18 published studies involving 564 fractures. Injury 2005;36(1):131-41. Crossref

20. Loizou CL, Parker MJ. Avascular necrosis after internal fixation of intracapsular hip fractures; a study of the outcome for 1023 patients. Injury 2009;40(11):1143-6. Crossref

21. Bhandari M, Devereaux PJ, Tornetta P 3rd, Swiontkowski MF, Berry DJ, Haidukewych G, Schemitsch EH, Hanson BP, Koval K, Dirschl D, Leece P, Keel M, Petrisor B, Heetveld M, Guyatt $\mathrm{GH}$. Operative management of displaced femoral neck fractures in elderly patients. An international survey. J Bone Joint Surg Am 2005;87(9):2122-30. Crossref

22. Roshan A, Ram S. Early return to function in young adults with neglected femoral neck fractures. Clin Orthop Relat Res 2006;447:152-7. Crossref

23. Butt MF, Dhar SA, Gani NU, Farooq M, Mir MR, Halwai MA, Kangu KA, Mir BA, Kawoosa AA. Delayed fixation of displaced femoral neck fractures in younger adults. Injury 2008;39(2):238-43. Crossref

24. Schwartsmann CR, Lammerhirt HM, Spinelli L de F, Ungaretti Neto A da S. Treatment of displaced femoral neck fractures in young patients with DHS and its association to osteonecrosis. Rev Bras Ortop 2018;53(1):82-7. Crossref

25. Zlowodzki M, Ayieni O, Petrisor BA, Bhandari M. Femoral neck shortening after fracture fixation with multiple cancellous screws: incidence and effect on function. J Trauma 2008;64(1):163-9. Crossref

26. Zlowodzki M, Brink O, Switzer J, Wingerter S, Woodall J Jr, Petrisor BA, Kregor PJ, Bruinsma DR, Bhandari M. The effect of shortening and varus collapse of the femoral neck on function after fixation of intra-capsular fracture of the hip: a multi-centre cohort study. J Bone Joint Surg $\mathrm{Br}$ 2008;90(11):1487-94. Crossref

27. Stockton DJ, Lefaivre KA, Deakin DE, Osterhoff G, Yamada A, Broekhuyse HM, O'Brien PJ, Slobogean GP. Incidence, Magnitude, and Predictors of Shortening in Young Femoral Neck Fractures. J Orthop Trauma 2015;29(9):e293-8. Crossref

28. Slobogean GP, Stockton DJ, Zeng B, Wang D, Ma B, Pollak AN. Femoral neck shortening in adult patients under the age of 55 years is associated with worse functional outcomes: Analysis of the prospective multi-center study of hip fracture outcomes in China (SHOC). Injury 2017;48(8):1837-42. Crossref 